\title{
Scimitar syndrome
}

\author{
Sevgi Pekcan ${ }^{1}$, Aysel Burcu Palandökenlier ${ }^{2 *}$ and Tamer Baysal ${ }^{3}$ \\ ${ }^{1}$ N. Erbakan University Meram Medical Faculty, Infantile Chest Diseases Field, Konya, Turkey \\ ${ }^{2} \mathrm{~N}$. Erbakan University Meram Medical Faculty, Infantile Cardiology Field, Konya, Turkey \\ ${ }^{3}$ Department of Pediatric Cardiology, Meram Medical Faculty, Necmettin Erbakan University, Konya, Turkey
}

\begin{abstract}
A rarely seen anomaly of pulmonary venous return, Scimitar syndrome is characterized by the opening of right side pulmonary veins into inferior vein cave or into the right atrium. this anomaly might be accompanied by such anomalies as right lung hyperplasia, bronchial anomaly, systemic arterial flushing of the lung (pulmonary sequestration) and dextrocardia. This single and expanded pulmonary vein is monitored in plain graphics as a shadow resembling a Turkish scimitar, extending from the mid-zone of the right lung towards the cardio phrenic angle. In our paper, a case is presented involving a child who we studied due to a frequently recurring lung infection and whom we diagnosed as inflicted with scimitar syndrome.
\end{abstract}

\section{Introduction}

Scimitar syndrome is a rarely seen return anomaly of the whole or partial pulmonary veins and is characterized by the opening of the right side pulmonary veins into the vein cave inferior (VCI) or into the right atrium. Pulmonary veins flows into the vein cave inferior just below or above the diaphragm. As the radiological image in the lung graphics of the expanded vein that extends in parallel with the right side of the heart up to the diaphragm is compared to the Turkish swords, it is called Scimitar symptom [1]. Although this characteristic image has been seen in the lung graphics in many cases, there are articles suggesting that this isn't a rule $[2,3]$. In this syndrome, tracheobronchial, cardiovascular and diaphragmatic anomalies may accompany, in addition to the pulmonary vein drainage anomaly; the partial hyperplasia of the right lung, the absence of any of the lob bronchi, diaphragmatic eventration, dextrocardia, arterial septal defect (ASD), venricular septal defect (VSD) are among the most commonly seen anomalies [4-6]. A child with Scimitar syndrome which demonstrated itself in the form of recurring lung infection and growth retardation and in which diaphragmatic eventration and ASD as the congenital heart disease accompanied and another child with the same syndrome who was identified in the course of research for growth retardation were presented due to the fact that they suffered from a rarely seen disease [7].

\section{Case 1}

While being monitored at an external center due to a growth retardation noticed by the family for two years, a girl, 11, was directed to our department of Child Diseases on the suspicion of the right lung hyperplasia. No active complaint was present, nor were there any drugs she took regularly. The miad was 2000 grams. She was admitted into the hospital once because of pneumonia. Her parents were not relatives with each other in any way. One of her sisters died at the age of 15 days, another at the age of 6 months and the other at the age of 9 months. The reasons are unknown. Upon physical examination, the body weight and length were below 3 percentile, and her examinations recorded in the system were normal. Her whole blood count, urine and blood biochemistry were all normal.

No anomaly was detected in the analysis of her blood gas. In the lung graph taken, a decrease in size in the right lung, chronic changes and a localized increase in ventilation in the left, as well as an image resembling a Turkish sword in the right side, were clearly visible (Figures 1 and 4). In the mesocardiac image of the heart in ECO, the flow pattern leading to the junction of the right atrium and the vein cave inferior was seen in a not venous image (ppvda?). The fluoroscopy conducted on the right diaphragm in terms of eventration was normal. An angiography was planned due to the suspicion of pulmonary venous return anomaly and the patient was hospitalized in the pediatric cardiology department. In the cardiac MR, pulmonary veins in the right side were seen to open into vein cave near the right atrium. Venous return anomaly was coherent (Figures 2 and 3). In the angiography, situs solitus mesocardy, partial return anomaly, the

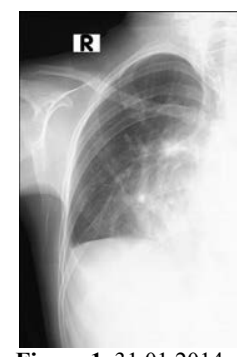

Figure 1. 31.01.2014

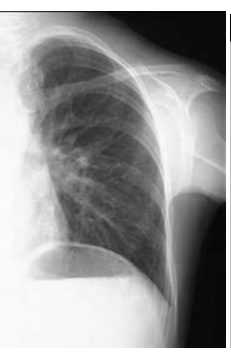

Figure 1. In P-A lung graph, Scimitar (Turkish Sword) finding. An arterial image is monitored that runs in parallel with the right side of the heart, expands and terminates at the diaphragm.

Correspondence to: Aysel Burcu Palandökenlier, Department of Pediatric Cardiology, Meram Medical Faculty, Necmettin Erbakan University, Konya, Turkey, Tel: +90 332 - 22363 49; E-mail: dr_aburcu@mynet.com

Key words: scimitar syndrome, partial pulmonary venous return anomaly, frequently recurring lung infection, child, infantile

Received: January 05, 2016; Accepted: February 09, 2016; Published: February 12,2016 


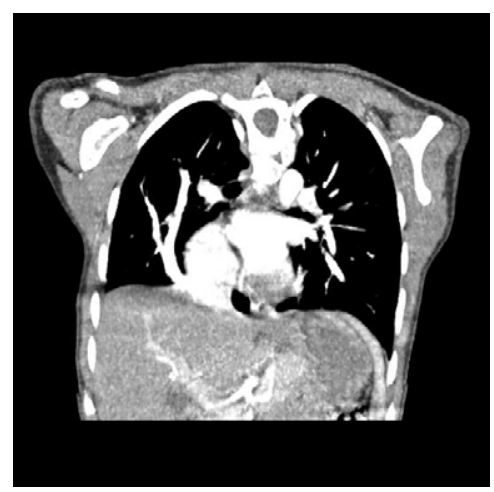

Figure 2. It is seen in the MR angiography that the right bottom pulmonary veins flow into vein cave inferior.

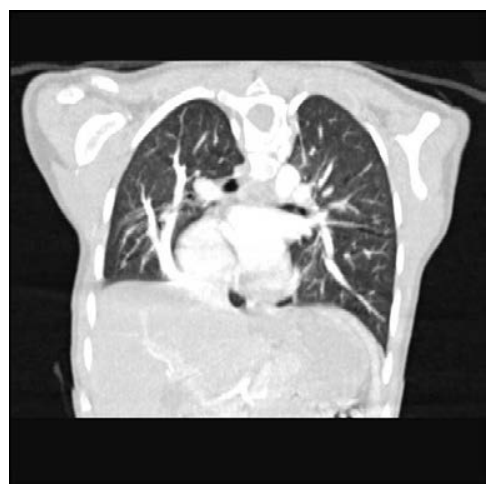

Figure 3. It is seen in the MR angiography that the right bottom pulmonary veins flow into vein cave inferior

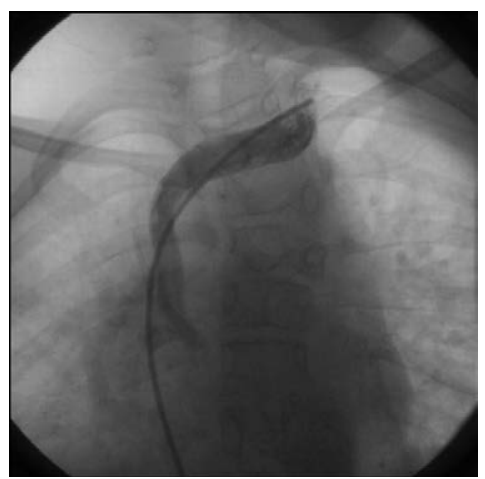

Figure 4. 04.02.2014 angiography

right heart structures were seen to be large, the right pulmonary artery was seen to open into the junction of ivk and the right atrium, and a slight pht was present (Figure 4). The existence of these symptoms suggested the Scimitar syndrome in the patient, and the patient was operated on June 13, 2014. In the cardiac operation, the anastomosis of the abnormal pulmonary veins in the right side with the left atrium and the closure of ASD were carried out.

The patient, who has been on followed by our department postoperatively for 1,5 years, has put on some weight and has grown taller.

\section{Case 2}

This patient, a girl who is two and a half years old, was brought to the clinic of chest diseases with the complaint of a cough which couldn't be eliminated even after a proper treatment of one month. It was understood from her history that, starting from the time she was four months old, she was taken to the hospital very often due to the cough and wheeze, she took antibiotics and used bronchodilator and was diagnosed to have ASD at the age of 18 months. She was then operated after the right diaphragm eventration was identified in her lung graph taken because of a recurring lung infection. The patient, whose complaints didn't come to an end, was being followed for one year with an inhaler steroid treatment.

In her physical examination, her weight and length were below 3. percentile, the count of her aspiration was 32 per minute, peak cardiac rate was 118 per minute and her body temperature was $37.1^{\circ} \mathrm{C}$. Common roncusses and secretuary rolls were present in both lungs of the patient, whose expersium was long when listened to, and she had no apparent symptoms other than $1 / 6$ ejection murmur in the heart. The patient's whole blood analysis, urine and blood biochemistry were normal. No abnormality was seen in her blood gas analysis.

In the lung graph taken, a decrease in size in the right lung, chronic changes and a localized increase in ventilation in the left, as well as an image resembling a Turkish sword in the right side, were clearly visible.

It was thought that atelectasis might be present in the right bottom zone and that there might be Sywer James Mcload syndrome because of a decrease in size in the right lung, and thus a lung tomography was demanded (Figure 5).

Peribronchial thickening in the left lung, a mosaic pattern and an opal image, a loss of volume in the right lung, an image that might be coherent with the anomaly in pulmonary vascular structures in the right lung and a slight displacement of the heart to the right were all observed in the computerized tomography (Figures 6a and $6 \mathrm{~b})$. In the echocardiography conducted, sinus venusus-type SAD (7-8 $\mathrm{mm})$ together with a slight dextroposition of the heart and a partial pulmonary venous return anomaly were observed. In the computerized tomography angiography (Figure 7) carried out to see whether a vascular anomaly was likely to exist, it was seen that the right bottom pulmonary veins flowed into vein cave inferior. Consequently, a diagnostic angiography was prescribed to the patient. The pulmonary arterial pressure was measured to be $25 / 5 \mathrm{mmHg}$ (10 $\mathrm{mmHg}$ on average); the right pulmonary veins were shown to flow into vein cave inferior (Figures $8 \mathrm{a}$ and $8 \mathrm{~b}$ ). Pulmonary secestration was not observed in the angiography. The patient, who had the existing partial abnormal pulmonary venous return anomaly, ASD, the right lung hyperplasia and improved diaphragm eventration history, was

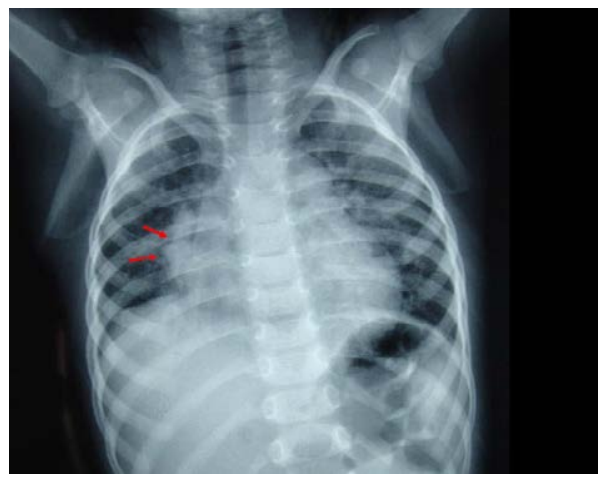

Figure 5: Scimitar (Turkish sword) finding in the P-A lung graph. An arterial image is obviously monitored that runs in parallel with the right side of the heart, expands and terminates at the diaphragm. 


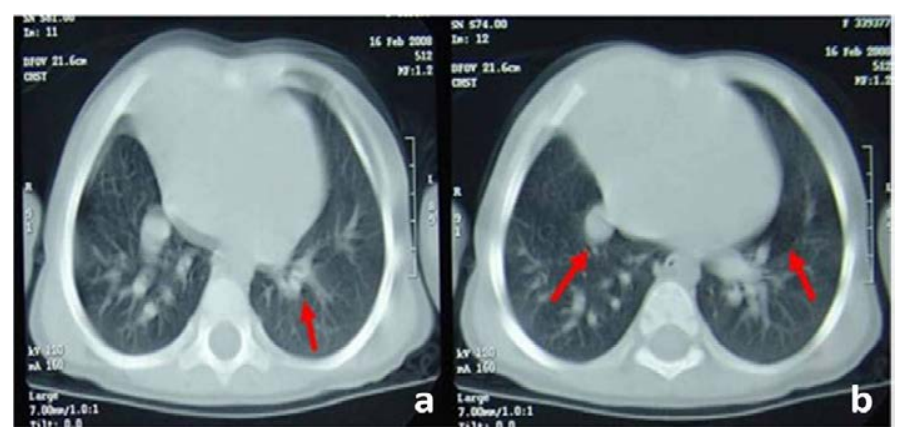

Figure 6: In computerized tomography, peribronchial thickening in the left lung, mosaic pattern and an opal image (a), an image that may be coherent with the anomaly in pulmonary vascular structures in the right lung (b).

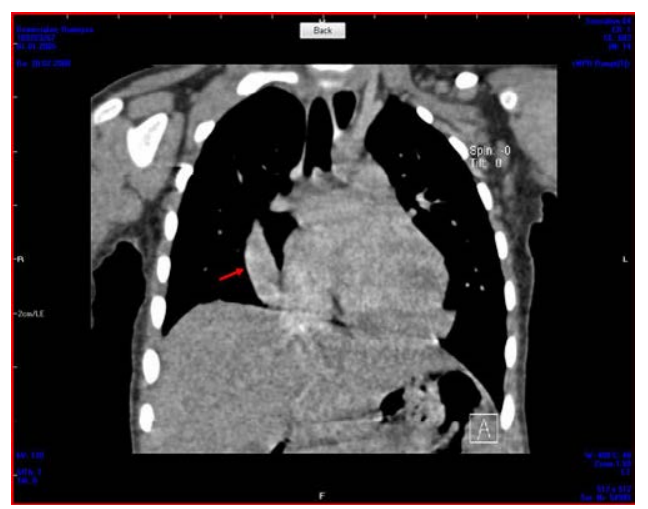

Figure 7: It is seen in computerized tomography angiography that the right bottom pulmonary veins flow into vein cave inferior.
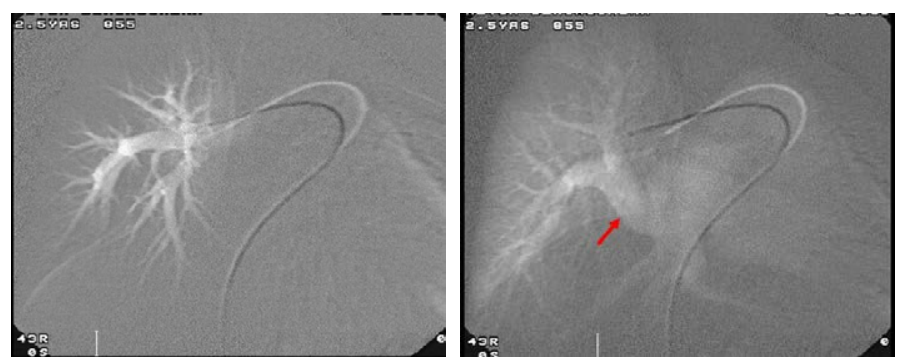

Figure 8: In diagnostic angiography, it is seen that the right side pulmonary veins flow into the vein cave inferior at the venous return phase after the injection (a) done to the right branch of the pulmonary arteries. diagnosed with Scimitar syndrome. A treatment of inhaler steroid and inhaler salbutamol was initiated on the patient due to the coherent nature with bronchiolitis obliterans because of the mosaic structure. A cardiac operation was also planned on the patient owing to the frequently recurring lung infection. During the cardiac operation, the anastomosis of the abnormal pulmonary veins in the right side with the left atrium and the closure of ASD were carried out. The patient, whose treatment of inhaler steroid and inhaler salbutamol was terminated just after the surgery and who has been on the follow-up by our clinic for one year, has no problem.

\section{Results}

The prognosis of the patients in Scimitar syndrome, a rarely seen natal cardio-pulmonary malformation, is determined by the degree of the lung hyperplasia and the majority of the accompanying cardiac anomalies. The distinctive diagnosis of the recurring lung infections should also be kept in mind.

\section{References}

1. Lieberum B, Ten Cate WJ (1996) Diagnosis and therapy of thyroid tissue of the base of the tongue. HNO 44: 393-396. [Crossref]

2. Saydam S, Tiroidin gelișim anomalileri, In: İşgör A, (ed) Tiroit Hastalıkları ve Cerrahisi, İstanbul, 1. baskı, Avrupa Tıp Kitapçılık Ltd. Şti, 2000: 25-32.

3. Giovagnorio F, Cordier A, Romeo R (1996) Lingual thyroid: value of integrated imaging. Eur Radiol 6: 105-107. [Crossref]

4. Özahinolu C, Akçalı Ç, Kırolu F, Kanlıkama M, Özmen H (1987) Lingual tiroidler Türk Otolarengoloji Arşivi 25: 199-205.

5. Prasad KC, Bhat V (2000) Surgical management of lingual thyroid: a report of four cases. J Oral Maxillofac Surg 58: 223-227.[Crossref]

6. Quarracino M, Aguas S (2003) Lingual thyroid: a clinical case. Med Oral 8: 57-60 [Crossref]

7. Osma Ü, Tekin M, Topçu, Üstel M (1997) Lingual tiroid Kulak Burun Boğaz İhtisas Derg 4: 168-170.

Copyright: (C2016 Pekcan S. This is an open-access article distributed under the terms of the Creative Commons Attribution License, which permits unrestricted use, distribution, and reproduction in any medium, provided the original author and source are credited. 